\title{
Autophagosome formation in relation to the endoplasmic reticulum
}

\author{
Yo-hei Yamamoto and Takeshi Noda* ${ }^{*}$
}

\begin{abstract}
Autophagy is a process in which a myriad membrane structures called autophagosomes are formed de novo in a single cell, which deliver the engulfed substrates into lysosomes for degradation. The size of the autophagosomes is relatively uniform in non-selective autophagy and variable in selective autophagy. It has been recently established that autophagosome formation occurs near the endoplasmic reticulum (ER). In this review, we have discussed recent advances in the relationship between autophagosome formation and endoplasmic reticulum. Autophagosome formation occurs near the ER subdomain enriched with phospholipid synthesizing enzymes like phosphatidylinositol synthase (PIS)/CDP-diacylglycerol-inositol 3-phosphatidyltransferase (CDIPT) and choline/ethanolamine phosphotransferase 1 (CEPT1). Autophagy-related protein 2 (Atg2), which is involved in autophagosome formation has a lipid transfer capacity and is proposed to directly transfer the lipid molecules from the ER to form autophagosomes. Vacuole membrane protein 1 (VMP1) and transmembrane protein 41b (TMEM41b) are ER membrane proteins that are associated with the formation of the subdomain. Recently, we have reported that an uncharacterized ER membrane protein possessing the DNAJ domain, called ERdj8/DNAJC16, is associated with the regulation of the size of autophagosomes. The localization of ERdj8/DNAJC16 partially overlaps with the PIS-enriched ER subdomain, thereby implying its association with autophagosome size determination.
\end{abstract}

Keywords: Autophagy, Autophagosome, Endoplasmic reticulum, ERdj8/DNAJC16, Atg2, VMP1,TMEM41b, ATG9, COPII, PIS, CDIPT

\section{Background}

Autophagy (specifically macroautophagy) is an intracellular degradation system that maintains cellular homeostasis and is associated with many pathophysiological phenomena, including cancer and neurodegenerative diseases $[1,2]$. Autophagy involves membrane structures called autophagosomes, which envelop the substrates and subsequently fuse with the lysosomes, resulting in the degradation of the substrates [3]. In the last 30 years, the molecular mechanism of autophagosome formation has been progressively understood. Autophagosome formation is controlled by a group of proteins called Atg

*Correspondence: takenoda@dent.osaka-u.ac.jp

Center for Frontier Oral Sciences, Graduate School of Dentistry, Osaka

University Graduate School, 1-8 Yamadaoka, Suita, Osaka 565-0871, Japan proteins, which are evolutionarily conserved in eukaryotes $[4,5]$.

There are two types of autophagy: non-selective and selective. Non-selective autophagy engulfs cytoplasmic solution non-selectively, which includes soluble proteins among others. The diameter of non-selective autophagosomes is thought to be relatively uniform $(\sim 1 \mu \mathrm{m})$. Selective autophagy engulfs diverse substrates of various sizes while large autophagosomes enwrap large autophagic substrates such as mitochondria and bacteria [6-9]. The size of autophagosomes varies from a few hundred nanometers in diameter to over a micrometer $[10,11]$. Recently, we have reported that the ER resident membrane protein, ERdj8/DNAJC16, is involved in the size determination of autophagosomes [12]. Herein, we original author(s) and the source, provide a link to the Creative Commons licence, and indicate if changes were made. The images or other third party material in this article are included in the article's Creative Commons licence, unless indicated otherwise in a credit line to the material. If material is not included in the article's Creative Commons licence and your intended use is not permitted by statutory regulation or exceeds the permitted use, you will need to obtain permission directly from the copyright holder. To view a copy of this licence, visit http://creativecommons.org/licenses/by/4.0/. The Creative Commons Public Domain Dedication waiver (http://creativeco mmons.org/publicdomain/zero/1.0/) applies to the data made available in this article, unless otherwise stated in a credit line to the data. 
introduce recent advances in the relationship between autophagosome formation and endoplasmic reticulum.

\section{Main text}

The endoplasmic reticulum (ER) is an organelle that plays diverse roles, such as the synthesis of secreted proteins and membrane proteins [13], protein transport [14], misfolded protein degradation [15], lipid synthesis [16], and calcium storage [17].

The architecture of the ER is composed of a tubular network and sheet like structures; recent advances in super-resolution microscopy imaging techniques have revealed that the ER sheet structure consists of a dense assembly of ER tube structures [18] (Fig. 1). The tubular structures are maintained by a family of proteins termed reticulons $[19,20]$. Cytoskeleton-linking membrane protein 63 (CLIMP-63) is responsible for the maintenance of the sheet-like structures [21]. The tubular structures are maintained by constant membrane fission and fusion, while the GTPase Atlastin regulates ER membrane fusion $[22,23]$. Additionally, a type of subdomain within the ER, was recently identified; for example, a subset of ER membrane proteins such as Sec61b and Atlastin localize to specific regions within the ER [18].

The intracellular site where autophagosome formation takes place had earlier been the subject of controversy; however, it is now clear that it occurs near the ER subdomain called the omegasome [24] (Fig. 1). Double FYVE domain-containing protein (DFCP1) is a phosphatidylinositol 3-phsosphate binding protein that serves as a specific marker of omegasome [24]. Indeed, local turnover of phosphatidylinositol 3-phsosphate occurs in the omegasome by the balanced activity of class 3 phosphatidyl inositol 3-kinase complex containing Atg14L and phosphatase, such as MTMR3 [25, 26]. Ultrastructural analyses have revealed that autophagosomes emerge from the vicinity of the ER [27-29]. Further, autophagosome formation in yeast takes place near a specific region of the ER (ER exit sites) [30,31] and the nuclear membrane [32]. The ULK1 complex, a scaffold of Atg proteins, is localized in the tubular vesicular ER subdomain where autophagosome formation occurs [33].

Recent advances have helped in understanding the relation between ER and autophagosome formation. Several reports have demonstrated the critical role of Atg2 in the connection between ER and autophagosomes both in mammalian and yeast cells [34, 35]. Atg2 binds to the ER along with Atg9 and Atg18 to form autophagosomes at the contact site between the autophagosome and the ER subdomain [34, 36]. A part of Atg2 shows homology to Vps13, which transfers lipid molecules from one organelle to another at the contact site [37]. Indeed, Atg2 shows lipid transfer activity,

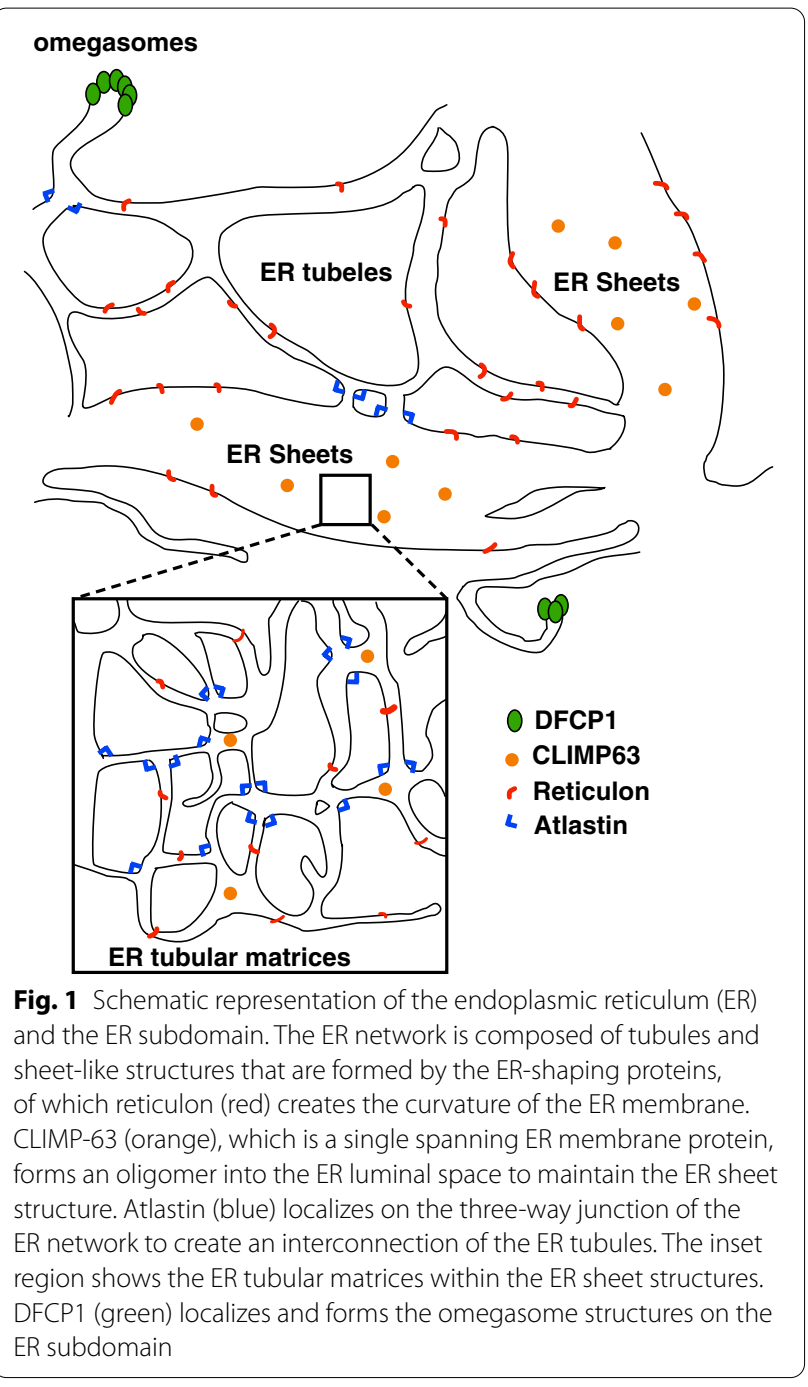

suggesting that lipid molecules flow from the ER to the autophagosome via Atg2 protein [35, 38, 39].

The lipid molecules that flow into the autophagosomes may not be preexisting ER constituents. Phospholipid synthases like phosphatidylinositol synthase (PIS)/CDP-diacylglycerol-inositol 3-phosphatidyltransferase (CDIPT) and choline/ethanolamine phosphotransferase 1 (CEPT1), accumulate in the ER subdomain and promote local lipid synthesis and elongation of the tube structure [40]. The small GTPase Rab10 is involved in the organization of the ER subdomain [40]. It is noteworthy that autophagosome formation takes place near this ER subdomain; the localization of the ULK1 complex occurs in the proximity of the PIS-enriched region [41]. Indeed, de novo phosphatidylcholine synthesis is required for autophagosome formation [42]. In yeast, de novo 
synthesis of fatty acids at the autophagosome formation site is further reported to be essential [43]. Therefore, it is possible that phospholipids synthesized near the autophagosome formation site are utilized. VMP1 is a multiple transmembrane ER protein [44-47]. Ablation of VMP1 inhibits the formation of PIS and CEPT1 subdomains of the ER [46] and leads to accumulation of the ULK1 complex and other autophagic machinery at the ER isolation membrane contact [47]. Another ER membrane protein called TMEM41b is also presumed to collaborate with VMP1 in these processes $[48,49]$. Thus, these proteins play pivotal roles in the ER subdomain involved in autophagosome formation.

Are these Atg2-mediated lipid transfers the sole lipid source of autophagosome membrane formation? Coat protein complex II (COPII) vesicles, which bud from the $E R$, are also suggested to be involved in autophagosome formation [50]. Atg9 is a transmembrane protein that localizes to the autophagosomal membrane and transports vesicles between the Golgi and endosomes [51]. The Atg9 vesicle, which is a transport vesicle in which the Atg9 protein resides, is further suggested to constitute a part of the autophagosome [52], although the other possibility is also discussed [51]. The involvement of recycling endosome derived vesicles has also been reported [53]. Future studies are needed to understand the full repertoire of the lipid source of the autophagosome membrane.

The ERdj proteins are a family of proteins harboring the DNAJ domain that cooperate with the molecular chaperones and play diverse roles in the ER [54-56]. Recently, we analyzed their uncharacterized member, ERdj8 [12]. ERdj8 was partially colocalized with PIS-enriched ER subdomains and also partially colocalized with Atg proteins (Fig. 2). When ERdj8 was ectopically overexpressed, there was an increase in the diameter of the autophagosomes in nonselective autophagy. When the expression of ERdj8 was knocked down, the size of nonselective autophagosomes was reduced. Moreover, knockdown or knockout of ERdj8 resulted in the failure of autophagosomes to enwrap large substrates such as mitochondria and latex beads with a diameter of $3 \mu \mathrm{m}$, while engulfment of smaller substrates such as paternally derived mitochondria or latex beads with a diameter of $1 \mu \mathrm{m}$ was not affected (Fig. 3. Based on

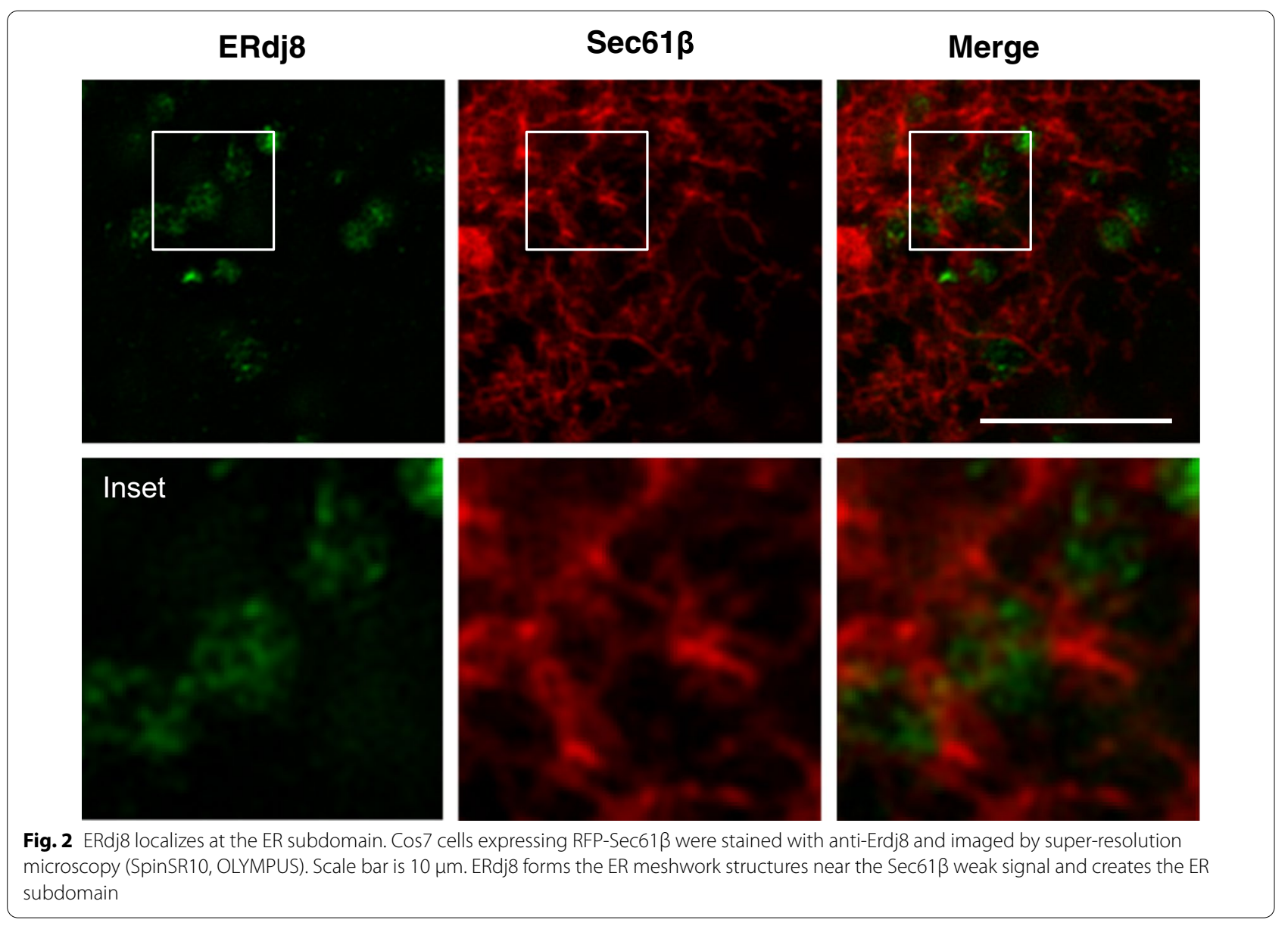




\section{a mitochondria (Large substrate)}

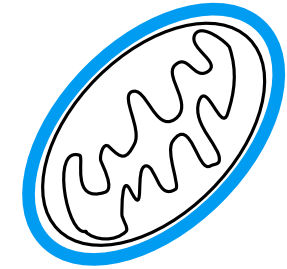

Cytosolic protein (Small substrate)

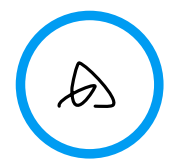

Autophagosomes

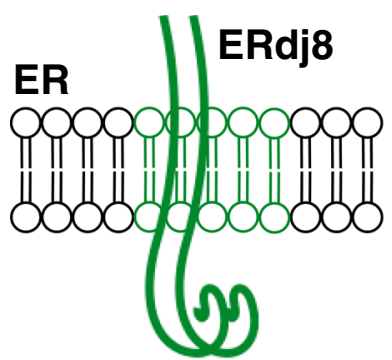

nomal expression b
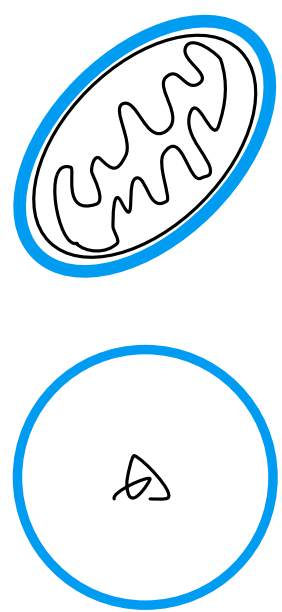

Large autophagosomes

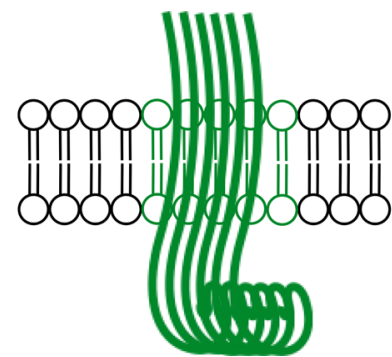

High expression
C
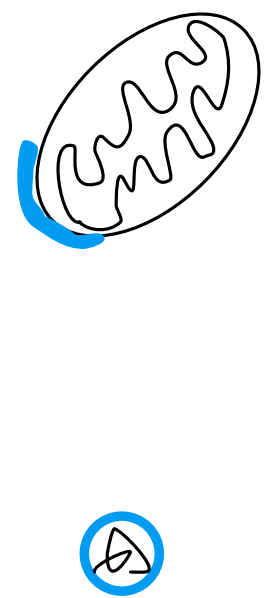

Small autophagosomes

Fig. 3 The expression level of ERdj8 alters the size of the autophagosomes. a Autophagosomes can capture both small and large substrates when ERdj8 expression is at the endogenous level. $\mathbf{b}$ ERdj8 overexpression induces the expansion of autophagosome membrane and both small and large substrates are degraded by autophagy. c Knockdown of ERdj8 induces the small autophagosomes to capture small substrates, whereas the degradation of large substrates is disabled

these results, we propose that ERdj8 regulates the size of the autophagosomes. The underlying mechanism remains to be determined; however, partial colocalization of ERdj8 with PIS may imply that ERdj8 affects the supply of phospholipids to the autophagosomes at the ER subdomain. VMP1 also colocalizes with PIS and CEPT1 on the ER subdomain, which suggests a functional relationship in autophagosome formation.

\section{Conclusions}

In this review, we have discussed how the ER is related to autophagosome formation. In this regard, current studies are expected to shed light on the mechanisms that regulate the size of the autophagosomes.

\section{Acknowledgements}

The authors thank Kazuhiro Nagata (Kyoto Sangyo University) for supporting the ERdj8 study. 


\section{Authors' contributions}

YY wrote the draft and TN finalized it. All authors read and approved the final version of the manuscript.

\section{Funding}

This study was supported by Grants-in-Aid for Scientific Research (KAKENHI) to $\mathrm{TN}$; and the joint research program of the Institute for Molecular and Cellular Regulation, Gunma University to YY.

\section{Availability of data and materials}

Not applicable.

\section{Ethics approval and consent to participate}

Not applicable.

\section{Consent for publication}

Not applicable.

\section{Competing interests}

There are no competing interests to declare.

\section{Received: 11 August 2020 Accepted: 2 October 2020}

Published online: 22 October 2020

\section{References}

1. Dikic I, Elazar Z. Mechanism and medical implications of mammalian autophagy. Nat Rev Mol Cell Biol. 2018;19(6):349-64.

2. Mizushima N. Autophagy: process and function. Genes Dev. 2007;21(22):2861-73.

3. Melia TJ, Lystad AH, Simonsen A. Autophagosome biogenesis: from membrane growth to closure. J Cell Biol. 2020;219(6):e202002085.

4. Mizushima N, Yoshimori T, Ohsumi Y. The role of Atg proteins in autophagosome formation. Annu Rev Cell Dev Biol. 2011;27(1):107-32.

5. Nakatogawa H. Mechanisms governing autophagosome biogenesis. Nat Rev Mol Cell Biol. 2020;21(8):439-58.

6. Kobayashi S, Kojidani T, Osakada H, Yamamoto A, Yoshimori T, Hiraoka $Y$, et al. Artificial induction of autophagy around polystyrene beads in nonphagocytic cells. Autophagy. 2010;6(1):36-45.

7. Mi N, Chen Y, Wang S, Chen M, Zhao M, Yang G, et al. CapZ regulates autophagosomal membrane shaping by promoting actin assembly inside the isolation membrane. Nat Cell Biol. 2015;17(9):1112-23.

8. Singh SB, Davis AS, Taylor GA, Deretic V. Human IRGM induces autophagy to eliminate intracellular mycobacteria. Science. 2006;313(5792):1438-41.

9. Yamaguchi H, Nakagawa I, Yamamoto A, Amano A, Noda T, Yoshimori T. An initial step of GAS-containing autophagosome-like vacuoles formation requires Rab7. PLoS Pathog. 2009:5(11):e1000670.

10. Jin $M$, Klionsky DJ. Regulation of autophagy: Modulation of the size and number of autophagosomes. FEBS Lett. 2014:588(15):2457-63.

11. Xie Z, Nair U, Klionsky DJ. Atg8 controls phagophore expansion during autophagosome formation. MBoC. 2008;19(8):3290-8.

12. Yamamoto $Y$, Kasai $A$, Omori $H$, Takino T, Sugihara M, Umemoto T, et al. ERdj8 governs the size of autophagosomes during the formation process. J Cell Biol. 2020;219(8):e201903127.

13. Anelli T, Sitia R. Protein quality control in the early secretory pathway. EMBO J. 2008;27(2):315-27.

14. Johnson $A E$, van Waes MA. The translocon: a dynamic gateway at the ER membrane. Annu Rev Cell Dev Biol. 1999:15(1):799-842.

15. Vembar SS, Brodsky JL. One step at a time: endoplasmic reticulum-associated degradation. Nat Rev Mol Cell Biol. 2008;9(12):944-57.

16. Lev S. Nonvesicular lipid transfer from the endoplasmic reticulum. Cold Spring Harb Perspect Biol. 2012:4(10):a013300.

17. Berridge MJ, Bootman MD, Roderick HL. Calcium signalling: dynamics, homeostasis and remodelling. Nat Rev Mol Cell Biol. 2003;4(7):517-29.

18. Nixon-Abell J, Obara CJ, Weigel AV, Li D, Legant WR, Xu CS, et al. Increased spatiotemporal resolution reveals highly dynamic dense tubular matrices in the peripheral ER. Science. 2016;28:354.
19. Voeltz GK, Prinz WA, Shibata Y, Rist JM, Rapoport TA. A class of membrane proteins shaping the tubular endoplasmic reticulum. Cell. 2006:124(3):573-86

20. Wang S, Tukachinsky H, Romano FB, Rapoport TA. Cooperation of the ERshaping proteins atlastin, lunapark, and reticulons to generate a tubular membrane network. eLife. 2016;5:18605

21. Shibata Y, Shemesh T, Prinz WA, Palazzo AF, Kozlov MM, Rapoport TA. Mechanisms determining the morphology of the peripheral ER. Cell. 2010;143(5):774-88.

22. Chang J, Lee S, Blackstone C. Protrudin binds atlastins and endoplasmic reticulum-shaping proteins and regulates network formation. Proc Natl Acad Sci USA. 2013;110(37):14954-9.

23. Orso G, Pendin D, Liu S, Tosetto J, Moss TJ, Faust JE, et al. Homotypic fusion of ER membranes requires the dynamin-like GTPase Atlastin. Nature. 2009;460(7258):978-83.

24. Axe EL, Walker SA, Manifava M, Chandra P, Roderick HL, Habermann A, et al. Autophagosome formation from membrane compartments enriched in phosphatidylinositol 3-phosphate and dynamically connected to the endoplasmic reticulum. J Cell Biol. 2008;182(4):685-701.

25. Matsunaga K, Morita E, Saitoh T, Akira S, Ktistakis NT, Izumi T, et al. Autophagy requires endoplasmic reticulum targeting of the PI3-kinase complex via Atg14L. J Cell Biol. 2010;190(4):511-21.

26. Taguchi-Atarashi N, Hamasaki M, Matsunaga K, Omori H, Ktistakis NT, Yoshimori T, et al. Modulation of local Ptdlns3P levels by the PI phosphatase MTMR3 regulates constitutive autophagy. Traffic. 2010;11(4):468-78.

27. Hayashi-Nishino M, Fujita N, Noda T, Yamaguchi A, Yoshimori T, Yamamoto A. A subdomain of the endoplasmic reticulum forms a cradle for autophagosome formation. Nat Cell Biol. 2009;11(12):1433-7.

28. Uemura T, Yamamoto M, Kametaka A, Sou Y, Yabashi A, Yamada A, et al. A cluster of thin tubular structures mediates transformation of the endoplasmic reticulum to autophagic isolation membrane. Mol Cell Biol. 2014;34(9):1695-706

29. Ylä-Anttila P, Vihinen $H$, Jokitalo E, Eskelinen E-L. 3D tomography reveals connections between the phagophore and endoplasmic reticulum. Autophagy. 2009;5(8):1180-5

30. Graef M, Friedman JR, Graham C, Babu M, Nunnari J. ER exit sites are physical and functional core autophagosome biogenesis components. MBoC. 2013;24(18):2918-31

31. Suzuki K, Akioka M, Kondo-Kakuta C, Yamamoto H, Ohsumi Y. Fine mapping of autophagy-related proteins during autophagosome formation in Saccharomyces cerevisiae. J Cell Sci. 2013;126(11):2534-44.

32. Baba M, Tomonaga S, Suzuki M, Gen M, Takeda E, Matsuura A, et al. A nuclear membrane-derived structure associated with Atg8 is involved in the sequestration of selective cargo, the Cvt complex, during autophagosome formation in yeast. Autophagy. 2019;15(3):423-37.

33. Karanasios E, Walker SA, Okkenhaug H, Manifava M, Hummel E, Zimmermann $\mathrm{H}$, et al. Autophagy initiation by ULK complex assembly on ER tubulovesicular regions marked by ATG9 vesicles. Nat Commun. 2016;11(7):12420

34. Kotani T, Kirisako H, Koizumi M, Ohsumi Y, Nakatogawa H. The Atg2-Atg18 complex tethers pre-autophagosomal membranes to the endoplasmic reticulum for autophagosome formation. PNAS. 2018;115(41):10363-8.

35. Valverde DP, Yu S, Boggavarapu V, Kumar N, Lees JA, Walz T, et al. ATG2 transports lipids to promote autophagosome biogenesis. J Cell Biol. 2019;218(6):1787-98

36. Gómez-Sánchez R, Rose J, Guimarães R, Mari M, Papinski D, Rieter E, et al. Atg9 establishes Atg2-dependent contact sites between the endoplasmic reticulum and phagophores. J Cell Biol. 2018;217(8):2743-63.

37. Kumar N, Leonzino M, Hancock-Cerutti W, Horenkamp FA, Li P, Lees JA, et al. VPS13A and VPS13C are lipid transport proteins differentially localized at ER contact sites. J Cell Biol. 2018;217(10):3625-39.

38. Maeda S, Otomo C, Otomo T. The autophagic membrane tether ATG2A transfers lipids between membranes. eLife. 2019;8:e45777.

39. Osawa T, Kotani T, Kawaoka T, Hirata E, Suzuki K, Nakatogawa H, et al. Atg2 mediates direct lipid transfer between membranes for autophagosome formation. Nat Struct Mol Biol. 2019;26(4):281-8.

40. English AR, Voeltz GK. Rab10 GTPase regulates ER dynamics and morphology. Nat Cell Biol. 2013;15(2):169-78. 
41. Nishimura T, Tamura N, Kono N, Shimanaka Y, Arai H, Yamamoto H, et al. Autophagosome formation is initiated at phosphatidylinositol synthaseenriched ER subdomains. EMBO J. 2017;36(12):1719-35.

42. Andrejeva G, Gowan S, Lin G, Fong A-CLWT, Shamsaei E, Parkes HG, et al. De novo phosphatidylcholine synthesis is required for autophagosome membrane formation and maintenance during autophagy. Autophagy. 2020;16(6):1044-60.

43. Schütter M, Giavalisco P, Brodesser S, Graef M. Local fatty acid channeling into phospholipid synthesis drives phagophore expansion during autophagy. Cell. 2020;180(1):135-149.e14.

44. Morishita H, Zhao YG, Tamura N, Nishimura T, Kanda Y, Sakamaki Y, et al. A critical role of VMP1 in lipoprotein secretion. Malhotra V, Pfeffer SR, Pfeffer SR, Prinz WA, editors. eLife. 2019;8:e48834.

45. Tábara L-C, Escalante R. VMP1 establishes ER-microdomains that regulate membrane contact sites and autophagy. PLOS ONE. 2016;11(11):e0166499.

46. Tábara L-C, Vicente J-J, Biazik J, Eskelinen E-L, Vincent O, Escalante R. Vacuole membrane protein 1 marks endoplasmic reticulum subdomains enriched in phospholipid synthesizing enzymes and is required for phosphoinositide distribution. Traffic. 2018;19(8):624-38.

47. Zhao YG, Chen Y, Miao G, Zhao H, Qu W, Li D, et al. The ER-localized transmembrane protein EPG-3NMP1 regulates SERCA activity to control ER-isolation membrane contacts for autophagosome formation. Mol Cell. 2017;67(6):974-989.e6.

48. Morita K, Hama Y, Izume T, Tamura N, Ueno T, Yamashita $Y$, et al.

Genome-wide CRISPR screen identifies TMEM41B as a gene required for autophagosome formation. J Cell Biol. 2018;217(11):3817-28.
49. Moretti F, Bergman P, Dodgson S, Marcellin D, Claerr I, Goodwin JM, et al. TMEM41B is a novel regulator of autophagy and lipid mobilization. EMBO Rep. 2018;19(9):e45889.

50. Shima T, Kirisako H, Nakatogawa H. COPII vesicles contribute to autophagosomal membranes. J Cell Biol. 2019:218(5):1503-10.

51. Noda T. Autophagy in the context of the cellular membranetrafficking system: the enigma of Atg9 vesicles. Biochem Soc Trans. 2017;45(6):1323-31.

52. Yamamoto H, Kakuta S, Watanabe TM, Kitamura A, Sekito T, Kondo-Kakuta C, et al. Atg9 vesicles are an important membrane source during early steps of autophagosome formation. J Cell Biol. 2012;198(2):219-33.

53. Puri C, Manni MM, Vicinanza M, Hilcenko C, Zhu Y, Runwal G, et al. A DNM2 centronuclear myopathy mutation reveals a link between recycling endosome scission and autophagy. Dev Cell. 2020;53(2):154-168.e6.

54. Kampinga HH, Craig EA. The HSP70 chaperone machinery: J proteins as drivers of functional specificity. Nat Rev Mol Cell Biol. 2010;11(8):579-92.

55. Ushioda R, Hoseki J, Araki K, Jansen G, Thomas DY, Nagata K. ERdj5 is required as a disulfide reductase for degradation of misfolded proteins in the ER. Science. 2008;321(5888):569-72.

56. Yamamoto Y, Kimura T, Momohara S, Takeuchi M, Tani T, Kimata Y, et al. A novel ER J-protein DNAJB12 accelerates ER-associated degradation of membrane proteins including CFTR. Cell Struct Funct. 2010;35(2):107-16.

\section{Publisher's Note}

Springer Nature remains neutral with regard to jurisdictional claims in published maps and institutional affiliations.
Ready to submit your research? Choose BMC and benefit from:

- fast, convenient online submission

- thorough peer review by experienced researchers in your field

- rapid publication on acceptance

- support for research data, including large and complex data types

- gold Open Access which fosters wider collaboration and increased citations

- maximum visibility for your research: over $100 \mathrm{M}$ website views per year

At $\mathrm{BMC}$, research is always in progress.

Learn more biomedcentral.com/submissions 